\title{
Material Types of Breeding Container of Dengue Vectors in Kuta Alam Sub-District Banda Aceh City
}

\author{
Farida Athaillah ${ }^{1 *}$, Nur A. Hashim ${ }^{2}$, Muhammad Hambal $^{1}$, Henni Vanda $^{1}$, Yudha Fahrimal, Wahyu E. Sari ${ }^{1}$ \\ Muttaqien Bakri ${ }^{1}$, Eliawardani Eliawardani ${ }^{1}$ and Lian V. Liandi ${ }^{1}$ \\ ${ }^{1}$ Faculty of Veterinary Medicine, Universitas Syiah Kuala, 23111 Banda Aceh, Indonesia \\ ${ }^{2}$ School of Food Science and Technology, Universiti Malaysia Terengganu, 21030 Kuala Nerus,Terengganu, Malaysia
}

\begin{abstract}
Aedes-borne arboviruses have emerged as an important public health problem throughout the world where Aedes spp. are the vectors responsible for this disease. This study was conducted to identify the material types of breeding containers of Aedes spp. larvae as one of the baseline data for Kuta Alam SubDistrict and to suggest suitable Aedes prevention and control strategies. Larvae were identified morphologically and larval indices were also calculated. A total of 2436 containers out of 14 types of containers observed during study periods. The positive breeding containers were surveyed and classified into indoors and outdoors environments. The material of positive breeding container types found was classified into six categories; cement, ceramic, plastic, metal, rubber and glass. As many as 450 of the 2436 potential containers included in the survey, half of the positive containers are cement and plastic materials which represent $80 \%$ of the total both in rural and urban areas, indoors and outdoors environment. It was followed by ceramic (15\%), metal (3\%) and rubber (1\%). Aedes spp. larvae were most abundant in cement and plastic material. Therefore, community mobilization towards eliminating human-made containers, either indoor or outdoor, is vital for the dengue control program.
\end{abstract}

Keywords: Aedes spp., arbovirus, dengue, material type.

\section{Introduction}

Dengue is the most prevalent and rapidly spreading mosquito-borne viral disease in the world. It has a worldwide distribution and is spreading over almost all tropical and subtropical countries [1]. The public health concern of Aedes mosquitoes because their role as vectors that can spread diseases such as Dengue, Malaria, Filariasis, Yellow fever, and Japanese encephalitis, chikungunya virus, and Zika Virus (ZIKV), The most common is the dengue virus which is transmitted to humans by the infected females of Aedes aegyti and Aedes albopictus. As the effective vaccine for dengue is not yet available, dengue control is limited to the reduction of the vector population [2]. Over half of the world's population is at risk of dengue and chikungunya infections [3].

It is affecting more than 50 million people each year [4]. Effort to control dengue has mainly involved insecticide spraying programs, but this strategy has proven ineffectual [5]. Dengue fever is transmitted to humans via the bite of infected Aedes mosquitoes. Aedes aegypti can adapt well to urban environments by breeding in clean or stagnant water in a wide variety of containers that collect rainwater such as tires, tin cans, pots, and buckets. For example, following the flood disaster in Brazil in 2008, 57,010 dengue cases including 67 deaths were reported among victims. This epidemic was associated with the disruption of basic water supply and solid waste management services. Other risk factors included changes in human behavior (e.g., sleeping outside and movement from non-endemic to endemic areas) and changes in habitat that promote mosquitoborne disease transmission [6].

Indonesia is the largest country in the region with a population of 245 million. Almost sixty percent of the people live on the island of Java, which is most severely afflicted by periodic outbreaks of dengue disease [7]. Epidemic Dengue Fever has been reported in all 27 Indonesian Provinces now whereas in 1968 only two provinces had reported dengue cases [8,9]. In Indonesia, dengue is a major annual public health problem causing cyclical epidemics in urban areas.

Therefore, the present study will be a contribution to determine some of the Aedes type of breeding habitats of the dengue vectors in Banda Aceh, which is essential for the planning of an effective mosquito control program to the future. The objectives of this study were mainly to identify the potential type of breeding habitats of mosquito and to identify mosquito larvae species whose dominated the type of within residential areas in urban and suburban area in Banda Aceh city. 


\section{Materials and Methods}

\subsection{Study sites}

The entomological survey was carried out in Banda Aceh located between $5^{\circ} 30^{\prime} 15^{\prime \prime}-05035^{\prime} 16^{\prime \prime}$ (North Latitude) and $95^{\circ} 22^{\prime} 15^{\prime \prime}-95022^{\prime} 35^{\prime \prime}$ (East Longitude) with average of an altitude of 0.80 meters above sea level. This area covers $61.36 \mathrm{~km} 2$. Banda Aceh encompasses 8 subdistricts, Kuta Alam subdistricts one of the 8 subdistricts and located in Banda Aceh. Banda Aceh has a tropical climate. An annual temperature varies between $25.50^{\circ}$ and $27.50^{\circ} \mathrm{C}$ (Anon, 2006) but can reach about $330^{\circ} \mathrm{C}-370^{\circ} \mathrm{C}$. A preliminary survey of breeding sites, Kuta Alam subdistrict was carried out before the study. Kuta Alam subdistrict is chosen for the implementation of the study, because Kuta Alam subdistrict is an endemic dengue area since 2007 and of eight districts in Banda Aceh that was affected by the earthquake and tsunami on 26 December 2004. Only this district has both urban areas and suburban areas. Therefore this subdistrict was chosen for the study. Kuta Alam sub-district consists of 11 villages. Two villages situated in urban areas name are Gampong Kuta Alam and Gampong Beurawe. These two villages are situated about 3-4 km from the sea (Gampong Kuta Alam is $3.2 \mathrm{~km}$ and Gampong Beurawe is $3.6 \mathrm{~km}$ from the sea), while the other two villages are in the suburban areas, situated about $1-2 \mathrm{~km}$ from the sea (Gampong Lampulo about $1 \mathrm{~km}$ and Gampong Lambaro Skep is about $1.6 \mathrm{~km}$ from the sea). The survey was done in these four villages.

The suburban area is a severely tsunami-hit area, without wooded areas, surrounded with a small number of vegetation areas, fewer modern buildings/houses and highly populated. Gampong Lampulo is a fishing village at the beach where the Fish Port and Industrial Zone Fisheries and Fish Auction Place (TPI) are located. Frequently, this village often encounter problem with water supply and relatively high levels of leakage and many pipes damaged by the tsunami.

Urban areas are referred to areas that were not affected by the tsunami and the central business district of Banda Aceh, which is a residential area with a lot of buildings and houses. Gampong Kuta Alam and Gampong Beurawe are dominated by public utilities, numerous with big trees in this area.

\subsection{Sampling methods}

Entomological surveys were carried out in the selected sites of the urban and suburban area in Kuta Alam subdistrict of Banda Aceh in 2010. They are Gampong Lampulo and Gampong Lambaro skep (suburban area) and Gampong Beurawe and Gampong Kuta Alam (the urban area). The field surveys were carried out in each study area between $0900 \mathrm{~h}$ and $1500 \mathrm{~h}$ by a three-person collection teams. Larval surveys were performed indoor and outdoor. Temperature, relative humidity and rainfall data during the period of study were obtained from the Banda Aceh Meteorological Service in Blang Bintang, Banda Aceh.

The Ministry of Health provided data on the occurence of dengue cases in Banda Aceh during the study period. Each survey consisted of inspection of the domestic and peri-domestic area, indoor and outdoor of each house in the selected study areas for water-holding containers. A general mosquito larval survey was performed by direct inspection inside and around all the 200 randomly selected houses for each study site for each period. Of 200 houses taken for sampling sites in suburban areas (100 houses from Gampong Lampulo and 100 others from Gampong Lambaro Skep) was randomly taken during the study period; while similar procedure was carried out in the urban area (100 houses from Gampong Beurawe and 100 others from Gampong Kuta Alam). All types of containers that could act as potential breeding sites and were water-filled (wet) and positive for mosquito larvae were recorded. Each container's characteristics (e.g. bottle, cup, tin, can) were described and categorized by the location (outdoors and indoors), and material types (plastic, glass, metal, rubber, cement or ceramic).

For all wet containers, the whole content was poured into ziplock plastic bags, while Aedes immature (larvae) from medium and large containers were collected using dipper or sieves then were placed into ziplock plastic bags. All plastic bags with samples were labeled with house and container names so that samples could be linked to the exact container and household from which they came. All samples in plastic bags were transported on the same day to the laboratory at Faculty of Veterinary Medicine, Universitas Syiah Kuala, Banda Aceh, Indonesia for further processing in the laboratory, labeled plastic bags containing Aedes immatures were examined. The 1st and 2nd instar larvae were reared for two days to allow the larvae to develop into 3rd or 4th instars to facilitate identification. All adults were identified using standard taxonomic keys by Rueda [2].

\subsection{Data Analysis}

The data quantitative analysis was performed using the Statistical Package for Social Sciences (SPSS) version 20.0 for Windows. Only positive water-holding containers were used for statistical analysis. Descriptive statistics, which include the percentage, mean and standard error of the mean, we're used to analyzing the characteristics of the positive water-holding containers (container types and the immature composition). Other descriptive statistics and inferential statistics like Chisquare tests were used for the test of the statistical significance. Percentages of A. aegypti or A. albopictus type of breeding sites and percentages of positive breeding sites with larvae were compared between urban and suburban areas using the Chi-square test.

\section{Results and Discussion}

\subsection{Percentage of Positive containers by basic material}

The type of materials of breeding containers found in Urban and Suburban areas are presented. Figure 1 showing the percentages of container type observed during the study period about concerning the types of material. The container types were classified into six 
categories; plastic, ceramic, metal, cement, glass and rubber. Almost half of the positive containers found in Banda Aceh city were plastic and cement materials as compared to others. They were more abundant than any other basic materials representing $80 \%$ of the total. It was followed by ceramics $(15 \%)$, metal $(3 \%)$, and rubber $(1 \%)$.

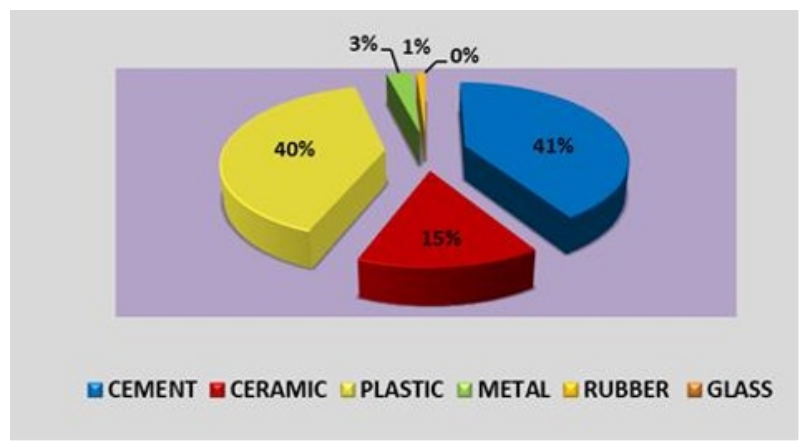

Figure 1. A percentage of positive containers by type of material of breeding containers in Banda Aceh city.

In Suburban areas, the number of different material types of the container between plastic, cement, metal, rubber, and glass showed a significantly different result $(\mathrm{P}<0.05)$. There were significantly difference percentages found between the number of cement and plastic found indoors compared to outdoors. Almost half of the indoors positive container (PC) (44.09\%) in Suburban were from of plastic materials, followed by cement material $(33.86 \%)$ compared to any other type of materials in the Suburban area $(\mathrm{P}<0.05)$. Whereas half of all of the outdoors PC $(50 \%)$ were based on cement materials, followed by plastic materials $(41.38 \%)$, metal $(6.89 \%)$ and rubber $(1.72 \%)$. There was no ceramic materials containers found outdoors environment, meanwhile, no glass, no metal, and no rubber materials were found at indoors environment.

Figure 3 shows the indoors and outdoors material types of containers in urban areas. The number of different types of materials between plastic, cement, metal, rubber, and glass showed a significant difference $(\mathrm{P}<0.05)$. There was a significant difference in percentages between the number of cement and plastic containers between indoors and outdoors PC. Almost half of the indoors PC (49.09\%) were based on cement materials and followed by plastic $(28.18 \%)$ compared to any other materials found in the Urban area $(\mathrm{P}<0.05)$. Whereas almost half of all of the outdoor PC (44.68\%) with Aedes immatures were found in plastic materials, followed by cement materials $(31.91 \%)$, metal $(21.28 \%)$. They were no ceramic and no rubber material containers in outdoor breeding sites.

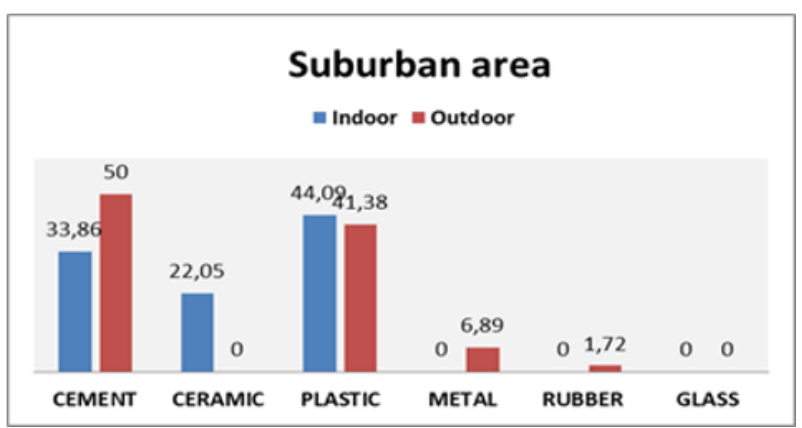

Figure 2. A percentages of positive containers by type of material indoor and outdoor in Suburban area in Banda Aceh city.

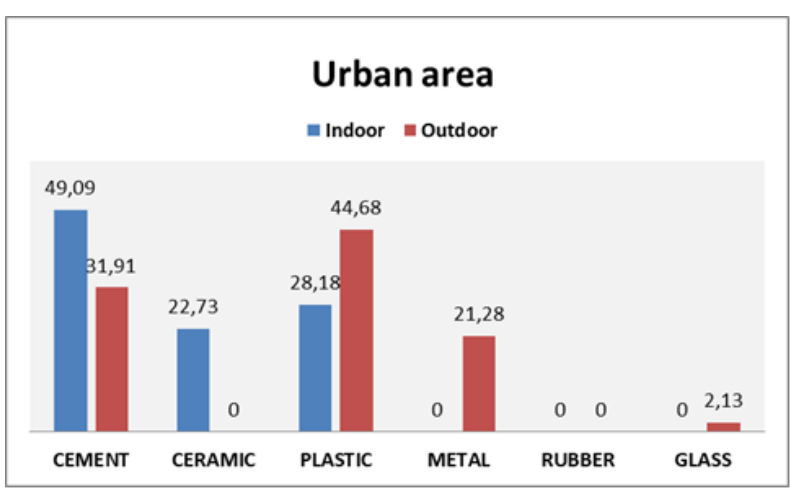

Figure 3. A percentages of positive containers by type of material indoor and outdoor in Urban area in Banda Aceh city Aceh Province.

Figures 4 and 5 show the percentages of material type of container that contained Ae aegypti and Ae. albopictus in an urban and suburban area in Banda Aceh. In urban area (Figure 4), most of Ae. aegypti immatures were found about $44 \%$ of them were found in cement containers, $38 \%$ in plastic, $17 \%$ in ceramic and $8 \%$ in metal material. Whereas Ae. albopictus immatures were mostly found in plastic and cement container in equal percentage (38\%), in metals $(15 \%)$ and in ceramics $(8 \%)$. No rubber and glass containers were found larvae in urban areas.

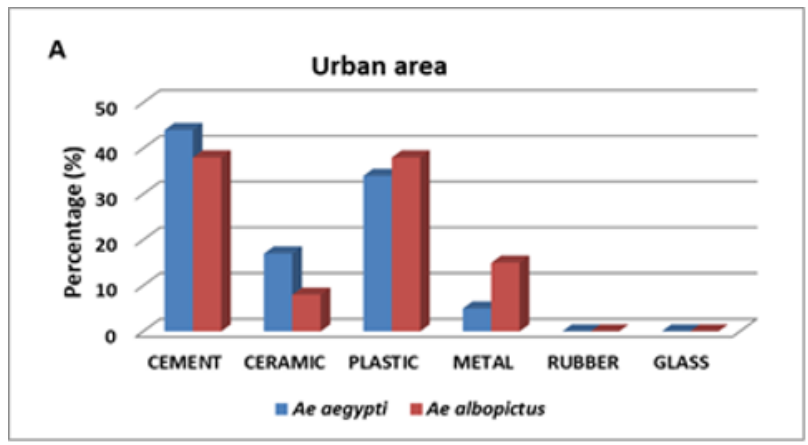

Figure 4. Percentages of container types that contained $\mathrm{Ae}$. aegypti and Ae. albopictus Urban area in Banda Aceh city. 
In the Suburban area (Figure 5), most of Ae. aegypti larvae were found in plastic $(45 \%)$ and cement materials $(39 \%)$. The rest were found in ceramics $(13 \%)$, metal (2\%) and rubber (1\%). No Ae. aegypti immatures were found in glass material containers. The same condition showed on Ae. albopictus immatures, that the dominant containers were cement $(42 \%)$, ceramics $(29 \%)$ and $(25 \%)$ in plastics. No Aedes immatures contained in rubber and glass material containers.

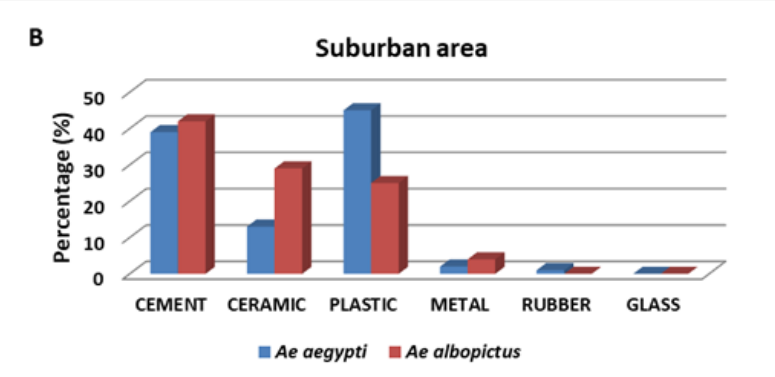

Figure 5. Percentages of container types that contained $A e$. aegypti and Ae. albopictus in suburban area in Banda Aceh.

The two areas selected in the present study differ in their physical settings as urban and sub urban areas. As many as 400 houses of both areas has been inspected in Banda Aceh City. All of these inspected had many household water storage containers. Entomological surveys in these areas revealed that 345 positive containers (PC) were collected. A total of 14 types of container habitats of Aedes mosquitoes were recorded in Banda Aceh located inside or outside the houses in urban and suburban areas during the survey. The common breeding habitats observed in the study area were wells, concrete tank, ceramic tank, plastic tank, water dispenser, bucket, refrigerator drip pans, drum, tin cans, earthen jar, glass plant pot, plastic plant pot, concrete pond, and tire. The most dominant PC are wells and tanks, both in urban and suburban areas. These studies on the distribution and relative abundance of mosquitoes in urban/suburban housing areas indicated that Aedes albopictus (Skuse) and Aedes aegypti (Linnaeus) were the most abundant. From this study, Aedes albopictus was found to be predominant when the survey was carried out in the outdoor areas. Aedes albopictus, is known to be a container breeder and mostly found in outdoor areas as supported by studies done by [10] who found that Aedes albopictus is a container breeder and it breeds in both natural and manmade habitats. While Aedes aegypti commonly breeds and feeds inside houses, Aedes albopictus is more common outdoor, in open spaces with shaded vegetation and suitable breeding sites such as plastic and cement materials as car tires and garbage dumps. Ae. albopictus is more likely to be found in natural containers or outdoor man-made habitats containing a greater amount of organic debris.

A similar result was found by [10] where both species Aedes albopictus and Aedes agypti was found to breed outside, rather than inside home dwellings. From the survey that has been conducted in the two localities which involved both urban and suburban areas. It was found that the main type of breeding habitats for mosquito were the same between these two areas. In urban and suburban areas major type of breeding habitat for mosquito was Plastic material and cement material. According to [10] in their study they also found the main potential type of breeding sites for Aedes spp. consisted of garden accoutrements. All containers containing Aedes albopictus were found outdoors, while three out of four containers positive for Aedes aegypti were also found outdoors. This study also indicated that the Aedes albopictus was the most dominant mosquito species that was found in both study areas.

The higher percentage of Aedes positive containers was in suburban areas compared to urban. This situation may be due to the majority of the residents in suburban areas in Banda Aceh City store tap and rainwater in containers for domestic use. Storing tap and rain water is a common practice due to irregular supply and preference of rainwater for laundry purposes. Due to poor rainfall and shortage of water supply, the residents stored water in various containers for a long duration and these containers constituted the major mosquito breeding sources. Containers that retained water for long periods make good or suitable breeding habitats for mosquitoes such as artificial containers [11]. Another reason was most residents here are not the original inhabitants, but came from the outside region. The owners of these houses don't want to stay there anymore; they were traumatized by the tsunami thus, the houses are rented/given to outsiders. This is the problem because most of the new tenants do not take full responsibility for the homes, the environment, and the sanitation. Most of the plumbing was damaged and leaked. This results in the lack of water supply, thus, people permanently store water indoor in large-sized containers; such as wells, drums, buckets, tanks, and others for daily use, createing an ideal breeding condition for Aedes immature stages thus increasing breeding occurrence inside homes.

The positive containers that provided mosquito breeding sites were found inside (indoor) and outside homes (outdoor). In the present study in Banda Aceh, the higher number of positive containers was encountered indoor as compared to outdoor environments. Most of the indoor containers were storage containers for example wells and tanks which were found in bathrooms and kitchens. All these containers as storage containers; they are usually kept for long periods and are sometimes unprotected from mosquitoes (uncovered), consequently becoming mosquito breeding places/sites. An Australian study found that underground habitats, such as wells, service pits, and septic tanks, comprised $15 \%$ total oviposition sites for Ae. aegypti and produced $85 \%$ of the total mosquitoes [12]. A similar result was reported by [13]. This happened because in the dry period when the small outdoor containers are dried out, this reduces outdoor breeding container's availability without influencing indoor breeding habitat which maintained the mosquito abundance in the indoors containers usually by large-sized containers that were used to store water for daily purposes. Therefore, more indoor positive containers PC were available as compared to outdoors PC. A similar finding was reported from Brazil by [14] where 
the storage containers were the predominant types of containers in the dry season, which was approximately threetimes the total number of all other types of containers found.

Cement material and plastic materials of breeding contaners were the most highly productive containers in terms of total immature collected during this study. These containers were permanently fixed (irremovable) in the bathroom, indoor or outdoor. Therefore, to prevent Aedes oviposition was to educate people on the importance of the container as a breeding site. Regular clean-up of the container, close the containers with the container cover and larvicide usage, would prevent mosquito breeding sites.

In the present study, a low number of A. albopictus (less than 15\%) were observed both in the urban and suburban areas probably due to urban area and suburban areas, whereby both of them have less vegetation. Thus, it can be concluded that vegetation plays an important role in container infestation by A. albopictus mosquitoes. Aedes albopictus preferred areas with high vegetation such as in rural and suburban areas, while the urban area with less vegetation was preferred by $A$. aegypti. Similarly, [15] found that A. albopictus favored habitats with more vegetation, whereas $A$. aegypti showed preference in habitat with less vegetation.

Therefore, understanding the ecology is important for outbreak prediction and effective planning of strategies to control transmission of arboviral infections. Studies on the ecology of $A$. aegypti are important to better understand the preference of the vector in terms of the oviposition and colonization of mosquitoes. The ecological factors play a role in influencing the population dynamics of larvae and pupae [16].

\section{Conclusions}

A conclusion, both A. aegypti and, A. albopictus immatures were most abundant in cement and plastic base material containers, whereas the least abundant were in the rubber and glass containers.

\section{Acknowledgments}

The authors are thankful to staffs of Laboratory of Parasitology Faculty of Veterinary Medicine, Health Office and Banda Aceh City Health Office for their assistance during the survey activities. The authors are grateful also to the students and driver of the Faculty of Veterinary Medicine for their assistance in the field survey.

\section{References}

1. Gubler D: Dengue/dengue haemorrhagic fever: history and current status. Novartis Foundation Symposium. 2006; 277:3-16.

2. Rueda LM: Global diversity of mosquitoes (Insecta: Diptera: Culicidae) in freshwater. Hydrobiologia. 2008; 595:477-487.
3. Kraemer MU, Sinka ME, Duda KA, et al.: The global distribution of the arbovirus vectors Aedes aegypti and Ae. albopictus. eLife. 2015; 4:e08347.

4. [WHO] World Health Organization: Dengue and dengue haemorrhagic fever. In: Fact Sheet. Word Health Organization, Geneva. http://www.who.int /mediacentre/factsheets/fs 117/en/. 2002; No.117.

5. [WHO] World Health Organization: Vector distribution and bioecology. In: Prevention and Control of Dengue and Dengue Haemorrhagic Fever: Comprehensive Guidelines. Regional Office for South-east Asia, New Delhi. 1999; pp 49-52.

6. [WHO] World Health Organization: Epidemic and Pandemic Alert and Response (EPR). Impact of Dengue. 2008.

7. Suwandono A, Kosasih H, Nurhayati, et al.: Four dengue virus serotypes found circulating during an outbreak of dengue haemorrhagic fever in Jakarta, Indonesia, during 2004. Trans. R. Soc. Trop. Med. Hyg. 2006; 100(9):855-862.

8. Sumarmo T: Dengue haemorrhagic fever in Indonesia. Southeast Asian J. Trop. Med. Pub. Health. 1987; 18:269274

9. Richards AL, Bagus R, Baso SM, et al.: The first reported outbreak of dengue haemorrhagic fever in Irian Jaya, Indonesia. Amr. J. Trop. Med. Hyg. 1997; 57(1):49-55.

10. Nur Aida H: Population abundance, forecasting models and breeding habitat ecology of dengue vectors in Pulau Pinang [dissertation]. Universiti Sains Malaysia, Pulau Pinang. Malaysia. Pulau Pinang. Malaysia. 2013.

11. Bhat MA, Krishnamoorthy K: Entomological investigation and distribution of Aedes mosquitoes in Tirunelveli, Tamil Nadu, India. Int. J. Curr. Microbiol. Appl. Sci. 2014; (10):253-260.

12. Russell BM, Kay BH, Shipton W: Survival of Aedes aegypti (Diptera: Culicidae) eggs in surface and subterranean breeding sites during the northern Queensland dry season. J. Med. Entomol. 2001; 38:441445.

13. Da-Silva JS, Ibiapina SS, Bezerra JMT, et al:: Variation in Aedes aegypti (Linnaeus) (Diptera: Culicidae) infestation in artificial containers in Caxias, State of Maranhão, Brazil. Rev. Soc. Bras. Med. Trop. 2012; 45(2):174-179.

14. Joelma S-da-Silva., Sebastiana SI, Juliana MTB, et al.: Variation in Aedes aegypti (Linnaeus) (Diptera, Culicidae) infestation in artificial containers in Caxias, State of Maranhão, Brazil. Rev. Soc. Bras. Med. Trop. 2012; 45(2):174-179.

15. Chen CD, Seleena B, Nazni WA, et al.: Dengue vectors surveillance in endemic areas in Kuala Lumpur City Centre and Selangor State, Malaysia. Dengue Bulletin 2006; 30:197-203.

16. Sang RC: Dengue in Africa. In: report of the scientific working group meeting on dengue. Geneva: WHO Special Programme for Research and Training in Tropical Diseases. 2007; pp. 50-52. 